\title{
Dinâmica, Espacialidade e Relações Homocomerciais: o exemplo das saunas de boys na urbe carioca ${ }^{1}$
}

\author{
Dynamics, Spatiality, and Homo-commercial Relations: the example of the sauna \\ boys in the city of Rio de Janeiro
}

Dinámica, Espacialidad y Relaciones Homocomerciales: el ejemplo de las
saunas de boys en la ciudad de Rio de Janeiro

\section{Miguel Angelo Ribeiro}

Universidade do Estado do Rio de Janeiro - Brasil

mamikisi@gmail.com

\author{
Dedico esse texto ao professor \\ Rafael da Silva Oliveira, com \\ estima e carinho.
}

\section{Resumo}

O objetivo deste artigo, pioneiro nos estudos geográficos, é analisar a dinâmica e a espacialidade das saunas masculinas de boys na cidade do Rio de Janeiro, além de discutir as relações homocomerciais em um clube privé localizado nessa cidade, fruto de pesquisas realizadas entre 2005 e 2011. Desse modo, uma pesquisa geográfica que se propõe estudar a espacialidade, a dinâmica e as relações comerciais dos prostitutos (boys) no Rio de Janeiro não poderia tangenciar um conceito tão caro à geografia - o de território. Sendo assim, o território e suas territorialidades relacionadas à prostituição e, especificamente, a masculina nas saunas, será um dos pilares que sustentará os estudos relacionados ao presente artigo.

Palavras-Chave: Espacialidade e Dinâmica; Relações Homocomerciais; Saunas de Boys; Território e Territorialidades; Cidade do Rio de Janeiro.

\begin{abstract}
The purpose of this article, a pioneer one in geographical studies, is to analyze the dynamics and spatiality of male saunas frequented by 'boys' in the city of Rio de Janeiro, besides discussing homo-commercial relations in a private club located in the city, from the results of researches carried out in the years 2005 and 2011. A geographical research that aims to investigate the spatiality, the dynamics, and the commercial relations of male prostitutes (also known as "boys" in Brazil) in Rio de Janeiro must also discuss a concept that is so dear to geography - the concept of territory. Thus, the territory and the prostitution related territoriality, specifically male prostitution in saunas, will be one of the pillars that will found the studies related to this article.
\end{abstract}

Keywords:spatiality and dynamics; homo-commercial relations; male saunas; territory and territoriality; Rio de Janeiro. 


\section{Resumen}

El objetivo de este artículo, pionero en los estudios geográficos, es analizar la dinámica y la espacialidad de las saunas masculinas de boys en la ciudad de Rio de Janeiro, más allá de discutir las relaciones homocomerciales en un club privé localizado en esta ciudad, fruto de las investigaciones llevadas a cabo entre 2005 y 2011. Una investigación geográfica que se propone estudiar la espacialidad, la dinámica y las relaciones comerciales de los prostitutos (boys) en Rio de Janeiro debe discutir también un concepto tan querido para la geografía como el de territorio. De esta forma, el territorio y sus territorialidades relacionadas con la prostitución y, específicamente la masculina en las saunas, será uno de los pilares que sustentará los estudios relacionados con el presente artículo.

Palabras-Clave: Espacialidade y Dinámica; Relaciones Homocomerciales; Saunas de Boys; Territorio y Territorialidades; Ciudad de Rio de Janeiro.

'O bom cliente é o que paga bem, não importa nada.' (Boy, 2005)

'Uma sauna de boys significa, basicamente, a entrada num mercado de sexo aberto, sem tabu, livre, descontraído, com enormes poderes de escolha e com opções de prazer sexual ao seu alcance.'

(Cliente, abril de 2014)

\section{Considerações Preliminares}

A prostituição masculina, na cidade do Rio de Janeiro, durante um longo tempo - do final do século XIX até o final dos anos 1970 - ficou restrita aos espaços públicos (MATTOS, 2002). Atualmente, este tipo de prostituição encontra-se em processo de desaparecimento na área central, local onde antes havia territórios configurados, como apontou Mattos e Ribeiro (1995), sendo atualmente encontrada em recintos fechados, por exemplo, saunas/private clubs de boys (saunas com relações homocomerciais) objeto de nosso estudo -, mas, também, oferecida em sites especializados através de serviços de massagem e acompanhantes. Seu crescimento pode ser explicado, entre outros fatores, em decorrência do aumento da violência ocorrida nos espaços públicos da cidade. Desse modo, a partir do início dos anos 1980 se gestou a prostituição fechada masculina no bairro de Copacabana.

Vale ressaltar que existem duas modalidades de saunas masculinas voltadas para o público gay no Brasil, em importantes metrópoles e algumas cidades de médio porte, a saber: as saunas de 'pegação' ${ }^{2}$ e aquelas com a presença de boys.

No caso do Rio de Janeiro, as saunas de pegação distribuem-se em maior número pelo espaço e são disseminadas pelos bairros do Leblon, Ipanema, Copacabana, Flamengo, Vila Isabel, entre outros, mas, possuem finalidades distintas das do segmento abordado neste trabalho. Como exemplo, podemos apontar que as saunas de pegação são espaços que não envolvem relações homocomerciais, diferente daquelas com presença de boys.

Neste contexto, podemos afirmar que a prostituição masculina fechada, exemplo das saunas e private clubs, já existe há mais de 
trinta anos, recebendo público, direcionado e exclusivamente gay, não somente do Rio de Janeiro, mas, também, de outros estados brasileiros e internacional. Esses espaços fechados configuram microterritórios, nos quais regras, normas de conduta, códigos e práticas são ditados por seus proprietários e devem ser previamente respeitados pelos boys e, também, pelos clientes, apresentando uma dinâmica extremamente singular (MAIA, 2007).

Outro ponto relevante a ser discutido nesta pesquisa diz respeito à espacialidade. Para Ribeiro, Oliveira e Maia (2011), de forma sintética, a territorialidade só se manifesta através do domínio e do controle social do espaço, e as relações empreendidas nesse microterritório possuem uma repercussão espacial segundo a materialidade local e da construção, apropriação e valorização simbólica dessas relações. A apropriação material e simbólica desse microterritório é exercida pela prática social dos atores, que o influenciam a partir da troca de papéis e da centralidade dos sujeitos envolvidos - boys e clientes (ORNAT, 2008).

A prática social da prostituição masculina incorpora as duas faces do mesmo processo: a expressão física e materializada no espaço, a partir dos diferentes ambientes; e a expressão simbólica, que se concretiza segundo códigos que identificam esse microterritório. Ele se encontra imerso em relações sociais pelo poder de afirmação e de representação do 'macho'. Nesse contexto, por meio das ações dos corpos, a mercadoria (SILVA et al., 2013) solicitada é o prazer, explorando "como eles são constituídos e usados, tendo como preocupação a inscrição do poder e a capacidade de resistência dos corpos envolvendo as questões de performatividade" (p. 89).

Posto isso, o objetivo deste artigo, pioneiro nos estudos geográficos, é analisar a dinâmica e espacialidade das saunas masculinas de boys na cidade do Rio de Janeiro, fruto do resultado de pesquisas entre os anos de 2005 e 2011, além de analisar as relações homocomerciais em um clube privé localizado nesta cidade.

Diante da problematização e do objetivo apresentados, três questões emergem para indagação do fenômeno: como se apresenta a dinâmica e espacialidade das saunas de boys na cidade do Rio de Janeiro; quais relações se estabelecem entre boys e clientes para configurar territorialidades; quais ambientes são identificados e que relações se manifestam entre os sujeitos no referido clube?

Para dar conta disso, cumpre mencionar a metodologia de pesquisa, que, de modo geral, tanto para as seções 2 e 3 , constituiu-se de trabalho de campo nas referidas saunas, conversas informais com clientes, entrevistas com boys e proprietários, levantamento fotográfico, além da pesquisa em sites específicos, coleta de materiais de propaganda, entre outros.

A referida metodologia foi dividida do seguinte modo: para tratar da espacialidade e da dinâmica das saunas (seção 2), foram realizadas visitas periódicas, entre 2005 e 2011, aos ambientes fechados em diferentes bairros da cidade do Rio de Janeiro. A variedade de locais permitiu perceber mudanças no conteúdo social, pois tais fixos, também conhecidos como 'casas de banho', apresentam entre si semelhanças e diferenças que trataremos adiante; e, para as relações homocomerciais, que terão como campo específico um clube privé selecionado, diferentes visitas foram realizadas, valendose da etnografia móvel (mobile ethnography) e levando em consideração os aspectos da observação participante e da análise das práticas discursivas, procurando dar conta do exemplo empírico selecionado (que será detalhado na seção 3).

Acerca do conceito de etnografia móvel, 
Oliveira (2014) aponta que este consiste em atribuir importância e, de certa forma, priorizar a pesquisa de campo a partir das micromobilidades. Aqui foi elaborado um esquema com o material coletado - que será exposto e detalhado na terceira seção - que procura retratar os diferentes ambientes onde as relações sociais se manifestam e se concretizam entre clientes e boys. São nesses distintos ambientes que transitam principalmente os rapazes de programa (boys) e clientes, além de funcionários, estabelecendo relações de contato e configurando territorialidades.

Dessa forma, uma pesquisa geográfica que se propõe estudar a espacialidade e a dinâmica, bem como as relações sociais dos prostitutos (boys) no Rio de Janeiro, não poderia tangenciar um conceito tão caro à geografia - o de território.

Diante do exposto, o artigo encontra-se estruturado em três seções. Na primeira, discute-se o conceito de território à luz da prostituição, em um contexto abrangente, além de tratar mais especificamente do conceito de 'nanoterritório' proposto por Souza (2013). Na segunda, procuramos analisar a espacialidade das saunas na urbe carioca, a dinâmica das relações cliente-boycliente e o perfil dos boys. Por fim, na terceira, discutem-se as relações homocomerciais, enfatizando pormenorizadamente a estrutura e os mecanismos internos de um dos mais importantes clubes do país, localizado em um bairro próximo à área central carioca.

\section{Territórío e Prostituição Masculina: uma análise teórico-conceitual}

Nesta seção propomos discutir, em um primeiro momento, o conceito de território associado à prostituição masculina em uma escala mais abrangente; e, em um segundo momento, abordaremos o conceito de 'nanoterritório' e a performatividade dos garotos de programa diante dos clientes.

\section{O território e a Prostituição Masculina em um Contexto Abrangente}

A questão do território deve, necessariamente, ser abordada quando nos propomos aprofundar o tema da prostituição nas saunas da cidade do Rio de Janeiro, pois entendemos que prostituição e território estão intimamente atrelados. Partimos, então, do conceito de território, entendido aqui como um espaço constituído com base em relações de poder (RIBEIRO \& MATTOS, 1995; SOUZA, 1995).

Quando falamos em território, o conceito nos remete à ideia de mediação entre as relações humanas. A geografia como ciência social mais ligada ao estudo desse conceito passa a ser responsável pela articulação entre o território e as duas bases que o delimitam: o espaço e o poder.

Os limites territoriais impostos pela prostituição se caracterizam de distintas formas nos espaços urbanos das grandes cidades. No Rio de Janeiro, encontraremos diferentes territorialidades de acordo com o bairro. Cada indivíduo ou grupo estabelece sua forma de demarcação, acesso, controle e território apropriado (SACK, 1986). A manutenção desse território depende diretamente da capacidade desse indivíduo ou grupo de exercer sua influência, impondo suas normas e condutas.

Devemos lembrar, contudo, que esse território possui delimitação simbólica, e os limites são impostos, em alguns casos, por meio do uso de violência como forma de legitimar uma posse. Para Campos (2000, p. 28):

a identificação simbólica refere-se aos diferentes significados e valores que o espaço assume para os 
diversos grupos sociais na busca da identificação; esta relação simbólica está muito diretamente associada às representações sociais. Essas representações são formadoras de uma trama complexa de diferentes significações que vão influenciar, motivar e mesmo justificar atitudes de resistência, defesa, animosidade dos grupos sociais em relação ao meio onde se encontram, do mesmo modo, as representações, construídas social e espacialmente, podem promover distinções de atratibilidade.

O território da prostituição possui uma especificidade bastante marcada, que consiste no fato de haver uma separação territorial nítida dos diferentes segmentos: prostitutas, michês (boys) e travestis. As observações de campo deixaram evidente que cada grupo delimita seu próprio território. Dessa maneira, não encontramos segmentos de travestis dividindo o mesmo espaço com prostitutas ou boys. Essa delimitação pode ser tênue, imperceptível ao olhar comum, mas a territorialidade se apresenta nitidamente para o olhar do geógrafo. Um exemplo elucidativo pode ser observado na avenida Atlântica, em Copacabana, onde uma quadra, uma rua ou alguns metros do mesmo logradouro ou quadra podem significar o limite dos diferentes grupos de profissionais do sexo (RIBEIRO, 1997).

Assim, a materialização de territórios de prostituição é produto da "instrumentalidade do espaço-poder-saber e forma a base para espacializar e temporalizar o funcionamento do poder" (RAFFESTIN, 1993, p. 159), enquanto a territorialidade, de acordo com Soja (1993, p. 183), teria como função "segregar e compartimentalizar a interação humana, controlando a presença/ausência e a inclusão/exclusão de outros grupos".
A territorialidade dos diferentes profissionais do sexo é definida não apenas pela iniciativa desses agentes, mas também por outros fatores que influenciam de forma decisiva na construção/desconstrução desse território. Dentre eles, quatro exercem maior influência para demarcar as áreas de atuação dos profissionais do sexo: intervenções frequentes por parte do poder público (polícia); dificuldade de acesso para os clientes (áreas periféricas); baixo poder aquisitivo dos possíveis clientes, rejeição por parte dos moradores locais e áreas muito degradadas.

Devemos salientar, contudo, que o território da prostituição, sobretudo a de garotos de programa (boys, michês), não se restringe aos espaços públicos. As saunas são espaços fechados com normas distintas daquelas toleradas nos espaços públicos ou abertos, onde a prostituição adquire territorialidades distintas. O território, nesses ambientes, tem um controle espacial mais intenso em decorrência das regras e normatizações impostas pelos proprietários dos estabelecimentos, e também pelos profissionais do sexo, que devem segui-las e definem a partir delas uma territorialidade específica, em um microespaço que adquire relações de poder hierarquizadas.

Cumpre mencionar a dimensão identitária do território, que consiste no laço afetivo que o indivíduo cria com seu entorno. Isto posto, não apenas $\mathrm{o}$ poder exerce influência $\mathrm{e}$ identifica a territorialidade, mas a identidade também contribui, a partir de laços afetivos criados entre o indivíduo e o lugar, os quais Tuan (1980) identificou como 'topofilia' - a ligação entre a pessoa e o lugar onde ela vive, criando uma relação afetiva entre o indivíduo e o ambiente físico, e, como exemplo, essa relação poderia ser transposta para a prostituição masculina e, neste caso, para os boys que frequentam as saunas de programa masculino. 
Nesse contexto, o próximo subitem será destinado a discutir em uma escala micro - a do 'nanoterritório' - a prostituição masculina e a performatividade dos garotos de programa diante dos clientes.

\section{O nanoterritório e a Prostituição Masculina}

A questão do território deve ser, necessariamente, abordada quando nos propomos a aprofundar o tema da prostituição masculina em um clube privé, pois entendemos que prostituição e território estão intimamente atrelados. Partimos, então, do conceito de território, entendido como um espaço constituído a partir de relações de poder (MATTOS; RIBEIRO, 1995; SOUZA, 1995; 2013).

$\mathrm{O}$ conceito de território nos remete à ideia de mediação entre as relações humanas. A geografia, na condição de ciência social, passa a ser responsável pela articulação entre o território e as duas bases que o delimitam: o espaço e o poder. Marcelo Lopes de Souza, ao rediscuti-lo, diz que "é, fundamentalmente, um espaço definido e delimitado por e a partir de relações de poder" (2013, p. 78), no qual relações sociais são realizadas. Em nosso exemplo, essas relações ocorrem entre boys/clientes/boys, além das teias de significados simbólicos. $\mathrm{O}$ território é definido por "campos de força, só existindo enquanto durarem as relações sociais das quais eles são projeções espacializadas" (SOUZA, 1995, p. 97).

Para Souza (1995, p. 87), os territórios são "antirrelações sociais projetadas no espaço que espaços concretos". Na verdade, estas relações de poder são espacialmente delimitadas e se realizam sobre um espaço concreto que serve de referência; no caso em tela - representado pelo clube de boys e seus diferentes ambientes -, travam-se relações que ora colocam o cliente na margem, ora no centro (ORNAT, 2008) em relação ao boy, travando um 'campo de força' no qual as relações homocomerciais se manifestam.

A dimensão das relações sociais ocorre através do poder, espacialmente materializado no território, manifestando um processo de territorialização em escala muito reduzida, mas plena de significados, que Souza (2013, p. 105) denomina "nanoterritórios", nos quais "as 'fronteiras' englobam uma rua ou um trecho de rua, um prédio ocupado por sem-teto, uma prisão, parcela das arquibancadas de um estádio de futebol" (p. 105), entre outros.

Esse 'nanoterritório' é flexível, pois se desfaz e refaz (SOUZA, 2013, p. 107) durante $o$ período de funcionamento, dependendo dos agentes que condicionarão a sua dinâmica social. Aqui temos como recorte um 'nanoterritório' fechado, privado, no qual o arranjo interno, ou seja, a disposição de seus ambientes, está sujeito a um processo de territorialização a partir da atuação e das relações de poder manifestadas pelos boys e seus clientes.

No processo de territorialização e na escala do 'nanoterritório', não podemos deixar de abordar a motilidade, discutida por Kaufmann (2002), de boys e clientes nesse microespaço. Como aponta Oliveira (2014), de acordo com o aquele autor, a motilidade é entendida como a forma pela qual um indivíduo se apropria do que é possível no domínio da mobilidade e coloca este potencial em favor de suas atividades. Assim, a motilidade abarca três elementos indissociáveis e inter-relacionados: acessos, habilidades e apropriações.

Transpondo esses três elementos para o nanoterritório analisado, podemos afirmar que os acessos correspondem às diferentes formas e graus de deslocamentos potencialmente disponíveis. Em nosso recorte espacial, o elemento físico é importante, principalmente por conta da 
utilização do corpo através das performances nos diferentes recintos (seção 3). Outro elemento importante corresponde às redes sociais existentes - de amigos, colegas, entre outras -, com potencial para promover encontros tanto no interior do clube como no espaço da rua. Já as habilidades estão atreladas à capacidade dos boys e clientes para reconhecerem e fazerem uso dos diversos ambientes existentes no estabelecimento. Estamos considerando que esse elemento da motilidade é constituído por habilidades físicas (como se deslocar de um recinto para o outro, percorrer os diversos ambientes, caminhar), habilidades adquiridas (saber abordar, 'caçar' o cliente, ou viceversa, a partir das diferentes performances) e habilidades organizacionais (planejar e sincronizar atividades, por exemplo). Por fim, as apropriações são entendidas como escolhas particulares (até mesmo a não ação), estando associadas às interpretações e ações diante do contato das habilidades com as possibilidades de acesso (reais, percebidas e imaginadas) apreendidas e reconhecidas no processo de territorialização. Desse modo, acessos, habilidades e apropriações constituem juntos a motilidade que auxilia nas práticas que ocasionam, por exemplo, as territorializações de boys e/ou clientes, no decorrer da permanência desses atores no estabelecimento.

Outro aporte conceitual importante para discutir as relações de boys e clientes diz respeito ao balé do lugar, conceito proposto por Seamon (1980), e que Oliveira (2002) utilizou em artigo sobre a territorialidade de travestis na área central de Nova Iguaçu, município da Baixada Fluminense, localizado na região metropolitana do Rio de Janeiro. Nesse estudo, o autor procurou "analisar a dinâmica das interações sociais e as coreografias do cotidiano por meio das quais se geram centralidades, abordando os fixos e a convergência para diversas direções, os fluxos" (OLIVEIRA, 2002, p. 149).

Para Seamon (1980), o balé do lugar é composto pelo tempo-espaço rotineiros e o balé do corpo. Em nosso recorte espacial - o clube privé -, o tempo-espaço rotineiros são aqueles empreendidos pelos boys e clientes ao chegarem ao clube, se despirem ou vestirem, voltarem para casa, entre outras, constituindo a coreografia daquele cotidiano vivido; e o balé do corpo, por sua vez, corresponde a movimentos como gestos, passos, performances dos clientes e dos boys, configurando a territorialização, de forma que o balé do corpo está intrinsecamente ligado ao tempo-espaço. Podemos afirmar que o balé do corpo, o tempo-espaço rotineiro e o balé do lugar unem pessoas ao espaço, lugar e tempo (OLIVEIRA, 2002). Neste balé do corpo, empreendido pelos boys e clientes, são estabelecidas relações de poder.

Em acordo com as ideias de Silva e Ornat (2011) para discutir um grupo de travestis, podemos afirmar que os boys, lutando pela sobrevivência naquele 'nanoterritório', muitas vezes se posicionam de forma central nas relações de poder: entre outros, quando determinam o preço do programa, o tipo de programa a ser feito (penetração, felação, posição passiva ou ativa) e o tempo de duração da atividade a ser realizada. Ao mesmo tempo, de forma paradoxal, podem se deslocar para as margens das relações de poder, passando a depender dos proprietários ou responsáveis pelo estabelecimento e dos clientes, que muitas vezes questionam o tipo de programa a ser realizado, impondo suas regras aos boys - ainda que caiba a estes aceitá-las ou não, em geral não têm alternativa, senão ceder para não perderem o programa, sendo coagidos pelas condições sociais e se posicionando, desse modo, à margem da relação.

Após estas considerações teóricoconceituais, passaremos à análise da espacialidade e dinâmica das saunas na 
cidade do Rio de Janeiro.

\section{A Espacialidade e a Dinâmica das Saunas na Cidade do Rio de Janeiro}

As saunas de boys apresentam entre si semelhanças e diferenças. As diferenças não se restringem apenas à localização, mas, principalmente, a uma série de fatores internos e externos ao próprio estabelecimento. Essas saunas estão distribuídas na urbe carioca por bairros da zona sul, da área central e entorno e do subúrbio. O preço e os serviços que cada estabelecimento oferecerá, é estabelecido, grosso modo, pela localização e pelos equipamentos disponibilizados aos clientes.

Para ingressar nas saunas (todas, sem exceção, cobram um valor de seus clientes e boys pela entrada), o preço estabelecido oscila muito de um bairro para outro - assim como ocorre com os demais serviços oferecidos em uma grande cidade. Dessa forma, o valor pode variar até $100 \%$ entre uma sauna localizada num bairro da zona sul diante de outra no subúrbio. Tal fato decorre de encontrarmos nas primeiras um ambiente mais requintado, decoração sofisticada que inclui iluminação indireta, plantas e cascatas artificiais. Com relação aos serviços oferecidos aos usuários, esses ambientes disponibilizam salas de vídeo, american bar, toalhas, sabonetes, xampu, entre outros itens.

Além das diferenças impostas pela localização e pelo público que frequenta, existe outra característica a ser percebida como determinante para distinguir uma sauna de 'pegação' de uma de boys. Algumas saunas contratam e oferecem aos clientes o serviço de prostitutos $^{3}$, que normalmente são rapazes jovens (entre 18 e 30 anos) que oferecem programas sexuais para os clientes. Em geral, as relações entre os profissionais do sexo e os clientes são tratadas e mediadas pelo empresário, proprietário ou gerente da casa, que é responsável pela organização do estabelecimento e decide o valor a ser cobrado pelo programa sexual, além dos preços das suítes a serem pagas pelos clientes. Os boys combinam o preço do programa diretamente com o cliente, para além do valor estipulado pela sauna, de acordo com as negociações sobre as práticas sexuais - por exemplo, a felação com uso ou não de preservativo, a relação envolvendo mais de um boy e clientes, entre outras. Em função dos vínculos de convívio estabelecidos entre boys e clientes, é possível acordar outros tipos de programas externos ao estabelecimento e em horários e dias alternativos, como frequentar a residência, ir a um hotel/motel e acompanhá-los em viagens e festas.

Nesses recintos, o atendimento aos clientes fica restrito ao horário de funcionamento do local e às normas internas impostas pelo empresário/proprietário/gerente da casa, configurando assim uma territorialidade específica bastante diferente daquela encontrada nas áreas de prostituição dos logradouros públicos. Um microterritório é, portanto, configurado, ficando clientes e boys sujeitos às imposições e passíveis de punição em caso de transgressão. Apesar de existirem diversos aspectos diferenciadores entre as saunas, como a variação dos preços e a qualidade dos serviços oferecidos, as regras e acordos estabelecidos são semelhantes.

Outro fator que aproxima tais estabelecimentos, fazendo com que essa semelhança seja percebida logo na entrada, diz respeito aos serviços oferecidos em seu interior: bares, suítes, boates, jogos, salas e dispositivos afins, bem como utensílios de higiene e segurança utilizados nas relações propriamente ditas - preservativos, cremes, produtos para banho.

Outra fonte de arrecadação existente nas saunas consiste no aluguel das cabines, que 
variam de tamanho e preço, onde ocorrem, efetivamente, as relações sexuais. Cumpre mencionar que os contatos iniciais entre clientes e boys realizam-se nos espaços internos do estabelecimento, como salas de banho, de recreação e lazer, corredores, boate e demais dependências.

Os códigos são bastante explícitos, ou seja, a prática de abordagem ao cliente, empreendida pelo garoto de programa, geralmente é por contato íntimo, buscando seduzir o usuário para consumação do ato sexual que será realizado nas cabines. Entre os recursos de sedução, destacam-se as performances dos garotos de programa, que circulam muitas vezes nus, exibindo seus atributos físicos de forma provocativa. Apesar dos diversos mecanismos de sedução, às vezes a negociação não se concretiza, e o programa sexual não se realiza.

No tocante às estratégias de aproximação e abordagem entre prostitutos e clientes, tanto no aspecto da escolha quanto ao preço extra a ser cobrado, percebeu-se que pequenos grupos de parceiros atuam em conjunto nas investidas aos clientes no interior das saunas, exercendo uma "disputa" por programas, ou trabalhando em conjunto.

$\mathrm{O}$ estigma e o imaginário construído em torno do estabelecimento pelos clientes e boys, assim como seus atributos físicos, influenciam decisivamente na mobilidade e/ou exclusividade do profissional do sexo. Em muitos casos, o boy associa a sauna em que trabalha como provedora do status ou depreciação de sua imagem, o que reflete na possibilidade de ganhos; portanto, muitas vezes, frequenta apenas um único estabelecimento ou private club que seja considerado pelo grupo de alto padrão. Ao mesmo tempo, a situação inversa também é evidenciada: boys que frequentam saunas consideradas de padrão inferior, comparadas às de melhor infraestrutura física e de higiene, não frequentam outras que apresentam status diferente.

Com base nos resultados estatísticos informados pelo projeto 'Babadão da Promoção da Saúde'4, cujos questionários foram aplicados entre outubro e novembro de 2007, podemos traçar um perfil social dos garotos de programa que trabalham nas saunas de relações homocomerciais. Em um universo de 127 questionários aplicados, mais de $55 \%$ dos rapazes têm entre 19 e 30 anos; no tocante à escolaridade, mais de $40 \%$ não apresenta o ensino médio completo, sendo que, desse total, $18 \%$ não possui ensino fundamental. Quanto ao local de procedência dos boys, $42 \%$ tem sua origem em municípios do estado do Rio de Janeiro, sendo que deste total $45 \%$ procede da Baixada Fluminense, notadamente de Duque de Caxias e Nova Iguaçu. Outros municípios que merecem destaque são Niterói e São Gonçalo.

Ao analisarmos tais resultados, podemos concluir que esses jovens apresentam nível de escolaridade baixo, residem em municípios que integram a região metropolitana do Rio de Janeiro e que apresentam problemas relacionados a uma realidade socioeconômica precarizada (OLIVEIRA, 2004; SIMÕES, 2006). Grosso modo, muitos se inserem nas relações homocomerciais em função de seu baixo grau de escolaridade e, consequentemente, da ausência de qualificação técnico-profissional, o que gera dificuldades para inserção no mercado de trabalho formal; outros se valem desse trabalho para complementar a renda para manutenção de suas necessidades cotidianas.

Nas saunas de relações homocomerciais, o risco da repressão policial é menor se comparado à prostituição nos logradouros públicos. A repressão comum que o Estado, através da polícia, exerce sobre esses territórios e as críticas que os moradores das respectivas áreas fazem, costumam ser menores pela discrição dos estabelecimentos 
- um mecanismo de proteção dos frequentadores e dos boys, não chamando atenção dos transeuntes e mantendo a privacidade dos frequentadores. Podemos aferir que tal situação é praticamente inexistente, ao contrário da prostituição de rua; os mesmos agentes que promovem a repressão no espaço público garantem, por meio de propina, a proteção e o funcionamento dos espaços privados.

Esses fixos sociais permaneceram com sua forma/aparência de antigas residências ou hotéis e passaram por um processo de refuncionalização para se transformar em saunas/private clubs específicos de relações homocomerciais.

Conforme matéria publicada no jornal $O$ Globo (2001), as casas de prostituição na cidade do Rio de Janeiro conseguiram, com nomes fictícios, registros em cartórios na junta comercial e licenciamento da prefeitura. Para escapar de processo criminal, os proprietários de alguns estabelecimentos burlam a fiscalização, mudando a razão social em alterações contratuais que indicam o verdadeiro ofício. Esse exemplo, que trata especificamente da prostituição feminina, pode ser transposto para o nosso objeto de estudo, pois os estabelecimentos de prostituição masculina também são considerados ilegais. Empresários encontram mecanismos para escapar de normas, códigos e leis municipais e estaduais e, assim, manter seus estabelecimentos funcionando. Também fazem 'acertos' periódicos com os agentes repressores do Estado (policiais), sendo o suborno o meio para manter uma relação de conivência e parcialidade.

Quanto à distribuição espacial das casas, há uma localização em áreas específicas da cidade. $\mathrm{Na}$ realidade, em 2007 foram registradas nove saunas, sendo duas no bairro da Glória (Club 177 e Sauna Spazio 18), uma na praça da Bandeira (Sauna Spa 73), três em Copacabana (Point 202, Estação e Roger's Termas), duas na área central (Club Meio Mundo e Caracalla) e uma no bairro de Cascadura (Club 89).

Em recente pesquisa realizada para confirmação da localização dos referidos estabelecimentos, por meio de sites especializados e contatos telefônicos, constatamos uma diminuição desse número, reduzido para cinco, conforme indicado no quadro a seguir (Quadro 1):

Os principais motivos que explicam essa diminuição podem ser compreendidos a partir de alguns elementos. $\mathrm{O}$ primeiro refere-se à concorrência das saunas, principalmente no caso do Club 117 (figura 1), considerado, para os padrões nacionais e cariocas, um dos melhores nesse serviço e motivo de propaganda em panfletos (figuras 2 e 3 ). Outro aspecto relevante é sua localização; o Club 117 fica próximo à área central, tem fácil acesso em decorrência da proximidade

Quadro 1 - Saunas/private clubs de boys, 2011.

\begin{tabular}{lc}
\hline \multicolumn{1}{c}{ Nome } & Bairro \\
\hline Club 117 & Glória \\
Club 89 & Cascadura \\
Club Meio Mundo & Centro \\
Point 202 & Copacabana \\
Sauna Spazio 18 & Glória \\
\hline
\end{tabular}

Fonte: Pesquisa de campo e análise em sites especializados entre os anos de 2005 e 2011. 
Dinâmica, Espacialidade e Relações

Homocomerciais: o exemplo das saunas de boys

na urbe carioca

Figura 1: Sauna Club 117, localizada na rua Cândido Mendes, bairro da Glória. Fotografado por Gessé da Silva Maia, 2007.

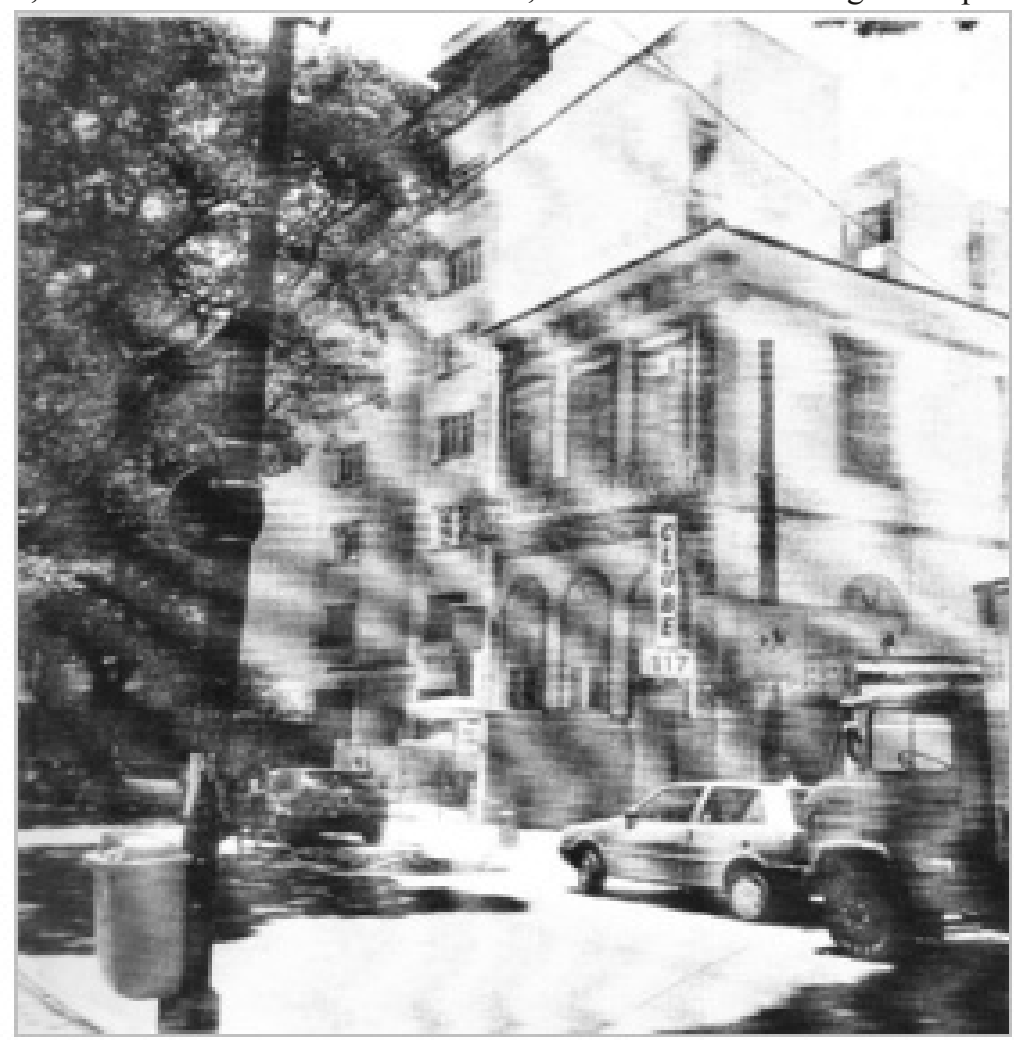

Figura 2: Panfleto coletado durante pesquisa de campo, agosto de 2010.

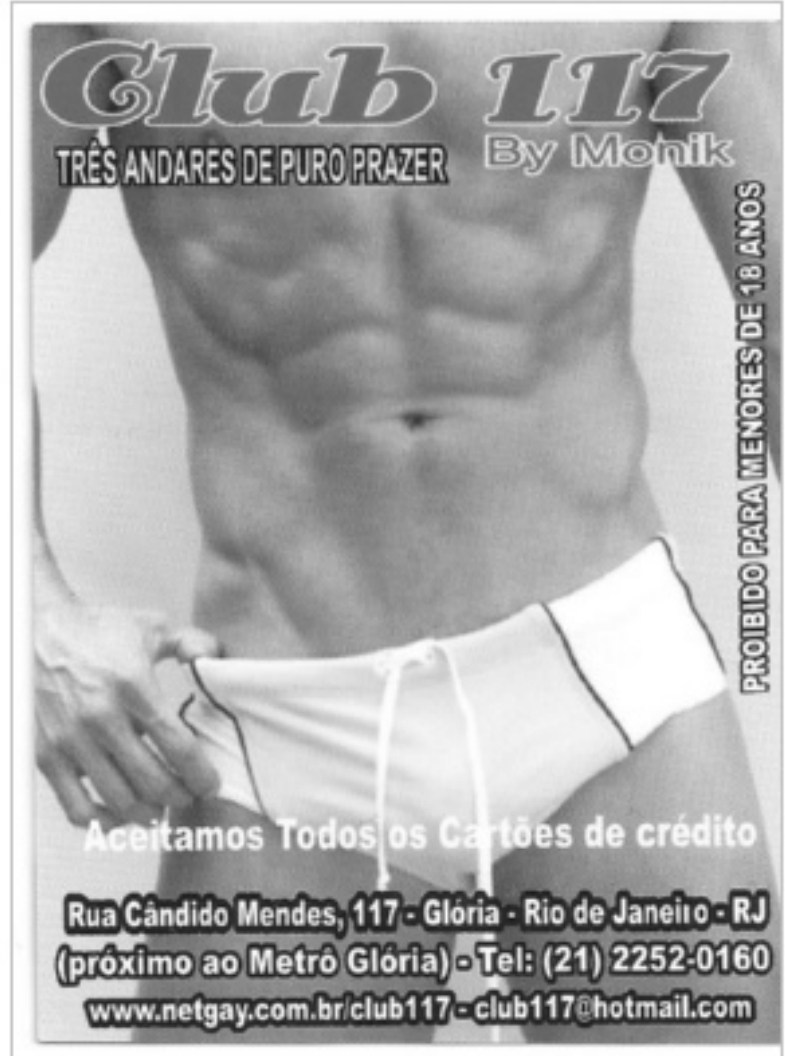

Figura 3: Panfleto coletado durante pesquisa de campo, agosto de 2010.

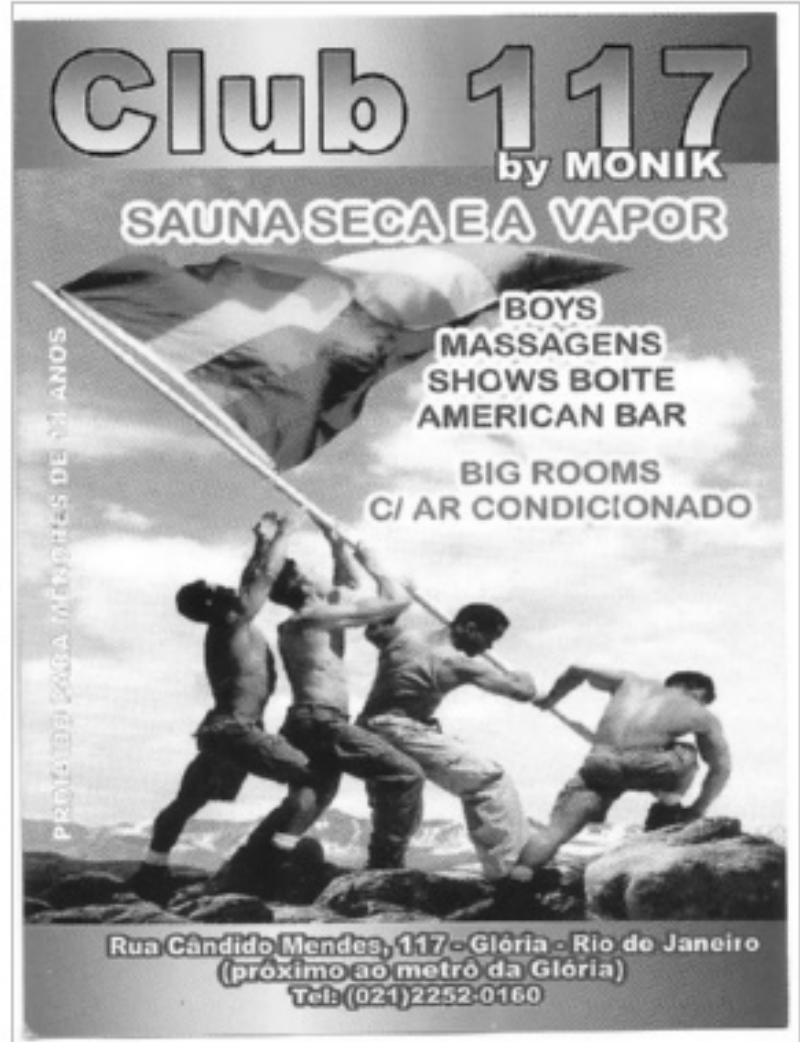

Miguel Angelo Ribeiro 
com uma das estações do metrô (Glória), além de várias opções de transportes urbanos.

Quanto ao término das atividades da sauna Caracalla (figura 4), situada na rua Mem de Sá, o motivo mencionado pelos clientes é a sua localização, na periferia imediata da área central, considerada 'perigosa'; além disso, a concorrência com as demais casas, que contribuíram para fortalecer o imaginário negativo e os preconceitos atrelados ao seu entorno.

A importância/relevância dessas saunas dentro do universo gay extrapola a sua dinâmica e rotina, chegando a assumir postura de militância junto ao movimento LGBT (lésbicas, gays, bissexuais, travestis e transexuais), patrocinando eventos e ao mesmo tempo promovendo suas atividades em paradas gays, passeatas e concursos de beleza gay.

Após a análise da espacialidade e da dinâmica das saunas na urbe carioca, o tópico seguinte tem por objetivo abordar os diferentes recintos e ambientes em um clube privé selecionado, em que, por meio de um esquema tridimensional, são analisados os papéis dos boys e dos clientes, configurando as diversas relações entre esses sujeitos.

\section{As Relações Homocomerciais: o exemplo em um clube Prive 1}

A escolha de um clube específico para análise empírica decorreu da importância e ressonância que este representa na cidade do Rio de Janeiro (RIBEIRO; OLIVEIRA; MAIA, 2011) e sua repercussão nacional e internacional - tendo espaço de divulgação em revistas especializadas e sites -, tornando-se pertinente a radiografia e análise desse 'nanoterritório' da urbe carioca (RIBEIRO; OLIVEIRA, 2014).

O clube está localizado no bairro da Glória, próximo à área central da cidade, em um casarão do início do século $\mathrm{XX}$, antiga

Figura 4: Sauna Caracalla, localizada na rua Mem de Sá, área central. Fotografado por Gessé da Silva Maia, 2007.

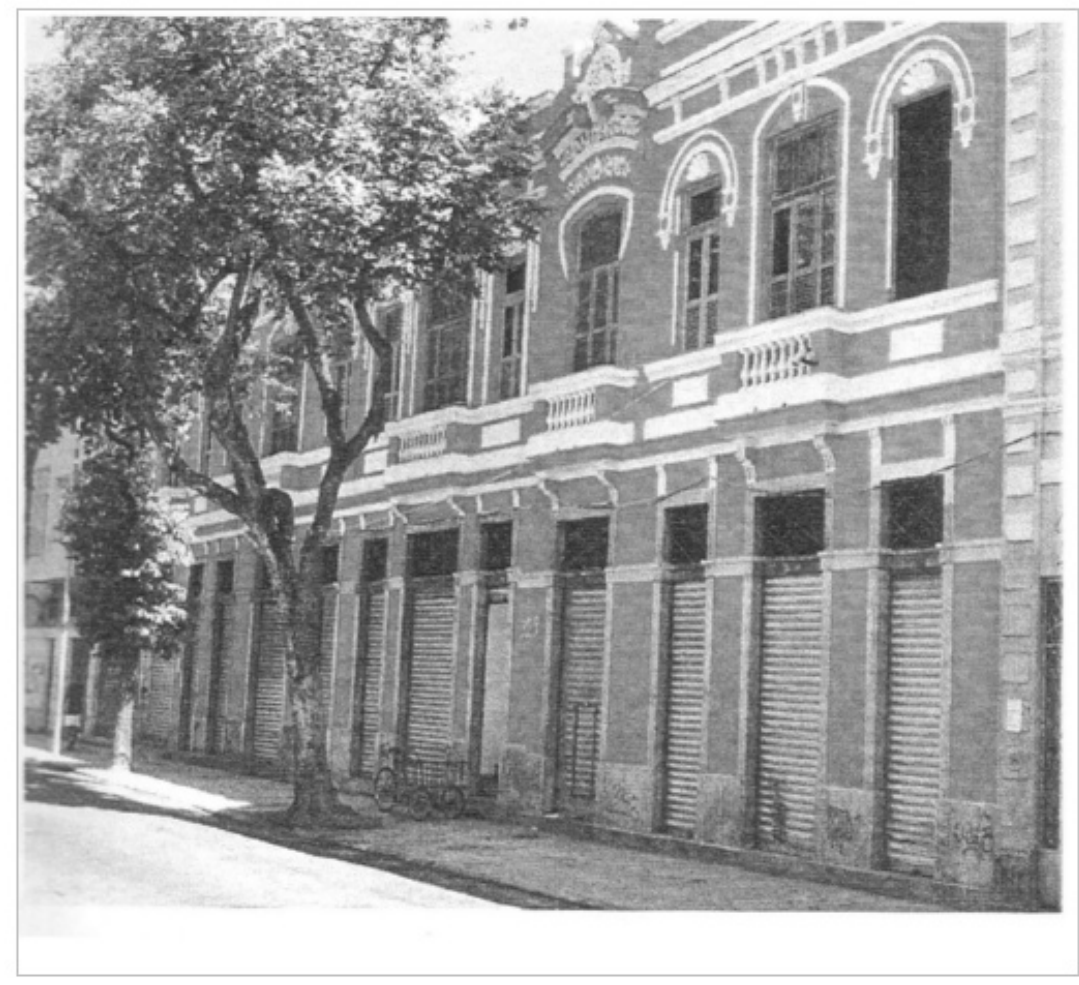


residência que mudou sua configuração interna para atender essa nova atividade. Como declarou sua proprietária/empresária (SILVA, 2014) em reportagem da revista S!:

[...] fui ousada diante desse mundo machista, mas tinha que ajudar as pessoas a terem seu local de liberdade e trânsito livre. [...] Assim me sinto independente de ser a única mulher no ramo no Rio de Janeiro ou no Brasil. Minha atitude 16 anos atrás [1998] foi bem aceita no ramo dominado por homens, como você mesmo diz. Estou feliz. Ser mulher ou homem foi o que menos me importou (p. 3).

Um cliente residente no exterior, em entrevista realizada por Ribeiro em 2014, declarou o que significa para ele o clube: "você está pagando pelo michê e por isso pode escolher o que você gosta, o que você tem tesão (é como num sonho)"; "Todos sabem que você vai lá para trepar e tratam o sexo com naturalidade, abertamente". E, por fim, o entrevistado aponta: "é como eu sempre digo: é como levar uma criança a uma loja de doces. Ela fica atônita no início, mas depois se esbalda".

Identificamos no clube os seguintes recintos, com seus distintos ambientes, distribuídos em três andares, conforme representado na figura a seguir (Figura 5).

$\mathrm{O}$ primeiro pavimento, que corresponde ao segundo andar, localizado no nível da rua, é constituído por:

Hall de entrada, que estabelece, a partir da porta principal, a separação entre o espaço da rua (externo - o público) e o espaço do clube (interno - o privado).

É interessante observar a chegada dos boys e dos clientes, muitas vezes tentando driblar as pessoas que passam pelo local, ainda que estas estejam alheias ao que representa aquele imóvel. Alguns clientes entram apressados, enquanto os boys procuram chegar de forma mais discreta possível. Os contatos entre boys e clientes na rua são evitados. Na entrada, seguranças dão apoio e taxistas fazem ponto, servindo aos frequentadores.

Recepção, onde um balcão separa os frequentadores dos funcionários (os recepcionistas) que cadastram clientes e boys após apresentação do documento de identidade. Também aí são fornecidas as chaves dos armários onde são guardadas as roupas e os pertences dos usuários e boys e realizadas as reservas de suítes para práticas sexuais mais íntimas, que não podem ser consumadas nos demais ambientes - apesar de alguns, por vezes, burlarem essa norma.

Neste ambiente, também é realizado o pagamento final dos serviços utilizados pelos clientes e boys quando deixam o estabelecimento. Geralmente o boy, quando acerta o programa na cabine, se encarrega de solicitar o material para a relação sexual (gel, preservativos), que será pago pelo cliente juntamente com a cabine. A chave do cliente é levada para registro. Dependendo do dia e da hora, muitas vezes há lista de espera para o recebimento da suíte (cabe mencionar aqui que $\mathrm{o}$ estabelecimento não funciona às segundas-feiras). O pagamento do cliente ao boy é separado daqueles que serão feitos ao clube na saída, em que estão incluídos, quando realizados, o consumo, a utilização das cabines e a massagem.

$\mathrm{O}$ cliente pode frequentar o clube exclusivamente para encontrar amigos e/ou assistir as atrações que são oferecidas, indicadas no quadro 2, a seguir. Além dessas atrações, promovem-se festas para comemorações especiais, como carnaval, shows, entre outros, permitindo estabelecer relações sociais diversas. 
Dinâmica, Espacialidade e Relações

Homocomerciais: o exemplo das saunas de boys

na urbe carioca

Figura 5: Recintos, ambientes e relações no nanoterritório. Fonte: Elaborado por Ribeiro e organizado por Oliveira a partir de pesquisas de campo (2011 a 2014)

\section{PRESENÇA}

1 Funcionários / Clientes / Boys

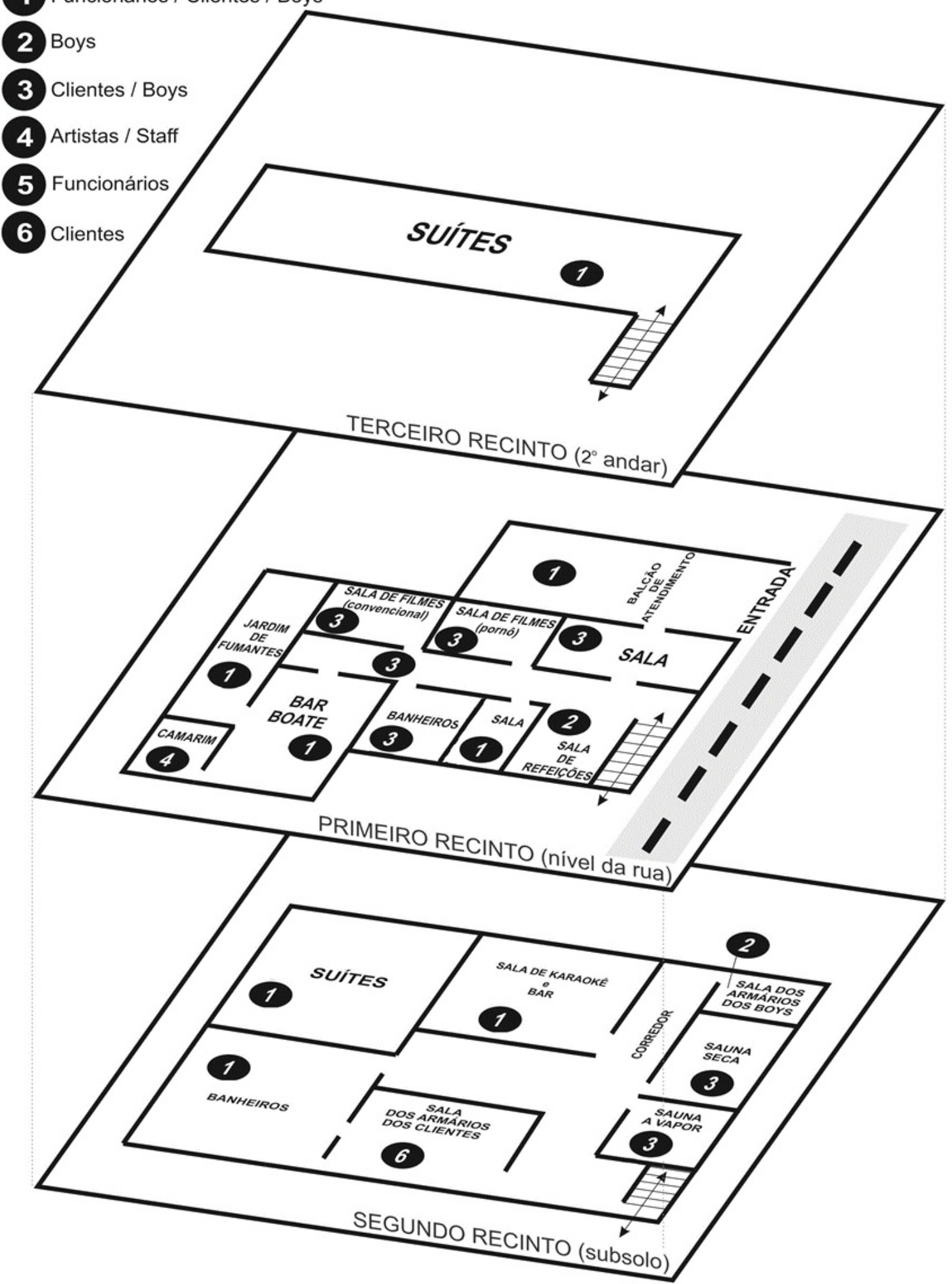

Miguel Angelo Ribeiro 
Quadro 2 - Atrações do clube durante os dias da semana.

\begin{tabular}{cl}
\hline $\begin{array}{c}\text { Dias da semana } \\
\text { Terças }\end{array}$ & \multicolumn{1}{c}{ Atrações } \\
Quartas & Show especial \\
Quintas & $\begin{array}{l}\text { Bingo especial com apresentação de um stripper boy } \\
\text { (sempre uma novidade a cada semana) }\end{array}$ \\
& Sempre uma apresentadora diferenciada com gogos em cena \\
Sextas & $\begin{array}{l}\text { Karina Karão e Fabyolla Nitchelly intercalam com Magaly } \\
\text { Penélope e Lord Talent, com convidadas }\end{array}$ \\
Sábados & Bingo com prêmios \\
& Especiais \\
Domingos & Karina Karão e Fabyolla Nitchelly intercalam com Samara \\
& Rios e Lord Talent \\
& Bingo com prêmios \\
\hline
\end{tabular}

Fonte: Elaborado por Ribeiro (2014) a partir de anúncio na Revista S!, ano XII, n. 139, p. 12

Cumpre mencionar que, já na recepção, as relações entre boys e clientes já se iniciam, com troca de olhares e, algumas vezes, conversas, iniciando os primeiros contatos.

Sala e corredor de passagem para banheiro, sala de massagem, sala de refeições e salas de televisão. No ambiente da pequena sala de entrada, tem-se o acesso por escada ao terceiro recinto, que corresponde ao segundo andar, onde estão localizadas as suítes, restritas aos clientes e boys que vão desfrutá-las para as atividades sexuais mais íntimas; e ao segundo recinto, correspondente ao subsolo. A partir desta sala, atinge-se o corredor no qual em uma extremidade encontramos o banheiro, a sala de massagem e a sala para refeição dos boys; e na outra extremidade estão as salas de TV e a porta que conduz à boate e ao bar.

$\mathrm{Na}$ sala e no corredor, onde os clientes se deslocam de um recinto para o outro, alguns boys de toalha ou totalmente nus ficam conversando e 'mirando' a clientela, e alguns se utilizam de códigos de postura, materializando uma microterritorialização, dentre eles apresentando seus dotes, tais como o membro endurecido, acariciando por vezes os clientes e dialogando na procura de um programa.

Em determinadas ocasiões, essas conversas entre boys e clientes, constituídas por 'toques' que resultam na combinação de preço e tipo de relação, se concretizam nas suítes, travando uma maior intimidade entre os sujeitos.

No espaço reservado às salas de $\mathrm{TV}$, no primeiro ambiente com sofá, programas televisivos de canais abertos são transmitidos. Alguns boys e clientes, dependendo da programação, assistem a jogos de futebol e programas de entretenimento.

Adentrando outro ambiente, com sofás e fila de cadeiras, os filmes pornôs são a atração - chama a atenção o fato de estes serem exclusivamente heterossexuais. Nesse espaço os boys se utilizam de códigos corporais para atrair os clientes, dentre os 
quais também o membro exposto, frequentemente masturbando-se. O máximo de contato que pode haver entre o boy e o cliente é o ato da felação, além da mão nas partes íntimas. Este local, geralmente, é controlado de forma discreta por funcionários, que podem chamar atenção, principalmente dos boys, quando estes se excedem na conduta ou norma permitida.

Conforme já mencionado, a partir de olhares e criando uma cumplicidade entre os envolvidos, muitos se aproximam e travam relações rápidas, para futuro encontro mais velado nas cabines, a partir da combinação do preço e do que será realizado. Por vezes, há nesse ambiente uma grande aglomeração de boys e clientes, configurando uma microterritorialidade; outras vezes, somente os boys aproveitam o referido espaço, até mesmo para descanso.

Alguns clientes apenas se aproveitam dos boys e não concretizam o programa para não pagar pela suíte e pelos serviços do boy. Os que ficam marcados por serem recorrentes nessa estratégia acabam preteridos. $\mathrm{O}$ banheiro eventualmente é utilizado por boys e clientes para transações rápidas, burlando as regras estabelecidas, já que são exclusivos para a satisfação das necessidades fisiológicas. A sala de massagem também é exclusiva para a referida atividade, com um massagista credenciado.

A boate/bar é outro ambiente de entretenimento, onde são realizadas as atrações indicadas no quadro 2 . Realmente se reproduz nesse espaço uma boate em dimensões reduzidas, constituída por um palco para shows, mesas, sofás e o bar com assentos. Neste recinto, clientes e boys conversam, dançam, jogam, paqueram, 'namoram', criando grupos de amigos. Com música ambiente, há divertimento, mas não transações sexuais.

Alguns clientes vão exclusivamente para encontrar amigos, fazendo do clube um local de sociabilidade. De acordo com um cliente, o local é "protegido e seguro. Ninguém vai roubar ou botar narcótico na sua bebida. Seus bens estão num 'locker'". Outros entrevistados dizem que vão exclusivamente à procura de boys, não permanecendo no ambiente da boate, e afirmam que "todos sabem que você vai lá para trepar".

O corredor de passagem com camarim é um ambiente entre a boate e o lounge externo. Nele está situado o camarim, no qual os artistas (transformistas, gogo boys) trocam de roupa (se montam) para os shows. É exclusivo para funcionários e artistas, não havendo envolvimento das relações entre boys e clientes.

Lounge externo. Este ambiente, localizado em parte externa do clube (varanda), é constituído por sofás, mesas, camas para descanso e um bar. Uma televisão de LED apresenta, de modo geral, clipes de shows nacionais e internacionais, além de jogos de diferentes modalidades esportivas. É o único ambiente onde se permite fumar. Os grupos de clientes e boys trocam conversas, carícias e combinam programas nas cabines. Algumas performances são executadas pelos rapazes de programa; outros transitam nus, a fim de seduzir a clientela. Nesse ambiente são consumidas bebidas, petiscos e refeições rápidas. Alguns boys aproveitam o contato com os clientes para se alimentar e beber.

$\mathrm{O}$ segundo recinto corresponde ao subsolo, localizado abaixo do nível da rua, chegando-se a este local por meio da escada localizada no primeiro recinto. É constituído por:

Sala dos clientes e banheiro. Constituída por armários (locker), bancos, bancada com pia e espelho. Exclusivamente para os clientes trocarem suas roupas e guardar seus pertences, sendo atendidos por um funcionário que lhes fornece toalha ou roupão e chinelo. Perto estão o banheiro e o mictório, também liberados aos boys. 
Nesses dois ambientes, os boys transitam em direção a outros locais do referido recinto. Muitos aproveitam para abordar os frequentadores, travando diálogo e primeiros contatos, enquanto outros utilizam o local para receber o pagamento do programa realizado.

Os armários dos boys são localizados em um corredor, ocupando um pequeno espaço. Eles trocam de roupa e colocam as toalhas e chinelos fornecidos pelo clube. Alguns permanecem de sunga, não se despindo totalmente, fazendo, de certa forma, mistério de seus atributos físicos. Nesse corredor estão dispostos bancos, nos quais, em alguns momentos, observam-se clientes que aproveitam para olhar a 'mercadoria' que será oferecida.

Alguns desses frequentadores já têm suas preferências e conhecem alguns boys, indo ao clube para o programa previamente combinado; do mesmo modo, alguns boys já criaram uma rede de relacionamento ${ }^{6}$, mantendo uma clientela fixa que contribui para o seu sustento. Outros, durante sua permanência no clube, têm que batalhar para conseguir realizar um programa, pois ficam à mercê do gosto do cliente.

$\mathrm{O}$ corredor serve ainda de passagem para boys e clientes que se deslocam para a sala de karaokê e bar, onde pequenas performances são realizadas por transformistas. Acreditamos que, devido à localização, este espaço é muito pouco utilizado. Em outro corredor, na sequência deste que descrevemos, são encontradas algumas suítes.

No ambiente onde estão os armários dos clientes, outro espaço é ocupado por um roupeiro, atendido por um funcionário, e há também mais duas suítes.

As saunas, seca e a vapor, e os chuveiros estão localizados em um corredor que liga a sala dos armários dos clientes e dos boys, em localização oposta. Antes de descrevê-los, cumpre apontar que alguns boys ficam parados neste corredor, procurando travar contato com os passantes e fazendo performances.

$\mathrm{Na}$ sauna seca, boys e clientes aproveitam para relaxar e manter contato, apesar de que esta é menos frequentada do que a sauna a vapor, onde, por vezes, há excesso de frequentadores. Muitos se dirigem a esses dois ambientes exclusivamente para relaxar, não travando diálogo ou relações com os boys. Outros travam diálogo e 'namoros' com os frequentadores, tentando seduzi-los para um programa nas suítes. Dependendo do momento e horário, esses ambientes ficam reduzidos a poucos frequentadores, podendo ocorrer algum tipo de relacionamento sexual entre eles, com pagamento inferior ao que se realiza na suíte.

Entre esses dois ambientes estão localizados os chuveiros, utilizados para banhos na chegada e saída de boys e clientes, ou nos intervalos de uso das saunas.

Por fim, no terceiro recinto, localizado no segundo andar do clube, estão localizadas as suítes, distribuídas por um corredor. Neste local há um funcionário que executa a limpeza após o término do programa. O espaço só é frequentado por aqueles que pagam pelas suítes. Essas suítes são consideradas as mais confortáveis, com banheiro privativo, cama de casal e televisão.

O tempo de permanência na suíte é de uma hora, conforme estabelecido pelas normas do clube. O cliente aluga a suíte paga ao estabelecimento por sua utilização. $\mathrm{O}$ preço do programa, como dissemos, é combinado diretamente com o boy. Ao término dessa hora, a chave deve ser entregue na portaria, caso contrário será cobrada uma hora extra.

Cumpre mencionar, ainda, que o cliente pode se dirigir à suíte com mais de um boy, dependendo do que foi estabelecido entre eles. 


\section{Arremates}

Entendemos que a geografia tem como compromisso refletir, entender e procurar explicar os fenômenos sociais que permeiam o nosso cotidiano. A prostituição, e aqui tratando da masculina no interior das saunas/private clubs, deve ser alvo de estudo por parte dos geógrafos, pois trata-se de um fenômeno presente no contexto dos centros urbanos e, portanto, ligado aos embates sociais que devem ser interpretados por esta ciência.

A cidade do Rio de Janeiro desponta, desde o século XIX, como cenário da gênese da prostituição masculina e apresenta, nos dias atuais, mudanças consideráveis em relação a esta atividade, sobretudo no segmento abordado neste artigo. Alguns empresários perceberam que agregar aos serviços oferecidos pelos boys a segurança e a privacidade que esses estabelecimentos proporcionam poderia atrair uma gama maior de clientes para seus estabelecimentos; estes são, sem dúvida, importantes agentes na manutenção e crescimento do fenômeno das saunas na cidade.

Entendemos, a partir deste artigo, que a prostituição masculina e os profissionais do sexo receberam novas denominações ao longo do tempo (de bagaxas a pederastas, michês, garotos de programa e boys), como também a sua função no cerne do espaço urbano continua em constante mutação. Tanto no passado quanto nos dias atuais, essa atividade continua a ser tolerada, mas não aceita. A necessidade dos serviços desses profissionais é latente para a manutenção das relações sociais na metrópole carioca. Notadamente, o enfoque moral ou "moralista e moralizante" já não está mais no centro das discussões e reflexões como no passado. Hoje, a atenção para as relações homocomerciais se volta mais a questões de saúde e sobrevivência dos boys e clientes, ainda que a atividade não esteja revestida da legalidade profissional.

A mútua construção simbólica de proteção/segregação lembra as discussões sobre a região moral, que se refere ao contexto e frequência de certas populações em se agruparem em áreas específicas do espaço urbano, sua mobilidade (trânsito) à procura de sexo, diversão, prazeres e 'outros vícios próximos à ilegalidade' (PERLONGHER, 1987). Tal compreensão abrange uma gama diversificada de espaços urbanos onde se constituem redes de relações sociais, que implicam modos de vida, linguagem, sinalizações e trocas entre sujeitos com vivências homocomerciais.

A prostituição masculina demarca seu território, e esta demarcação é seguida de territorialidades específicas de acordo com cada segmento dos profissionais do sexo. Dessa forma, tais profissionais impõem suas territorialidades, delimitando seus territórios com gestos, códigos e práticas; sobretudo, nos espaços abertos (logradouros), em que os rapazes de programa utilizam seus atrativos corporais para territorializar e, ao mesmo tempo, atrair seus clientes.

Convém mencionar, ainda, que este segmento da prostituição masculina sofreu um processo de retração de seus territórios nos espaços públicos do Rio de Janeiro, ao passo que a prostituição nos ambientes ampliou-se e foi acompanhada de formas distintas de territorialidades, além de guardar algumas especificidades.

Outro aspecto importante diz respeito à localização desses estabelecimentos acompanhando uma dinâmica que se relaciona ao status dos bairros a partir do valor dos imóveis e da procura dos serviços oferecidos pelos profissionais do sexo. Ainda nesse sentido, as saunas/private clubs são, em certos casos, agentes capazes de refuncionalizar espaços antes desprovidos de atividades, mudando sua função, mas 
mantendo em sua grande maioria as características da forma original.

Quanto à dinâmica interna em um clube gay, seu movimento diário é muito denso de significados. Nesse contexto, diferentes atores se manifestam em um processo de territorialização em escala micro, no qual o corpo ganha papel de destaque, por meio das mais distintas performances realizadas pelos boys.

Portanto, podemos afirmar que o processo de territorialização só se manifesta através do domínio e do controle social do espaço, representado e exemplificado neste artigo pelo clube em análise. Nesse contexto, 'o ato de observar é, ele mesmo, parte do espetáculo' (GOMES, 2013), no qual principalmente boys e clientes, através da motilidade, se apropriam do que é possível no domínio da mobilidade em favor de suas atividades, em que os acessos, as habilidades e as apropriações são importantes para configurar a microterritorialidade.

Desse modo, defendemos que a prostituição masculina fechada, representada em um clube específico, configura um nanoterritório, com suas territorialidades, imprimindo em cada recinto feições que identificam e demarcam uma centralidade, exercendo papel importante na sua organização interna e provocando uma interação entre rapazes de programa e clientes.

Como apontou um cliente, o clube representa "um lugar que expressa uma pseudoliberdade para os homossexuais, que procuram a satisfação sexual sem compromissos, segura e variada, já que há uma diversidade de homens disponíveis para o sexo pago".

$\mathrm{Na}$ verdade, podemos afirmar que a atividade da prostituição não deixa de representar, como apontam Silva et al. (2013), geografias malditas. Nesse contexto, essas temáticas envolvendo corpos, sexualidades e prostituição continuam sendo, no Brasil, "significativamente pouco estudadas e marginais no âmbito das geografias de gênero e sexualidades" (p. 9), vistas sob um viés moralista e preconceituoso por parte da comunidade geográfica e, também, pela sociedade. No entanto, não podemos menosprezá-las, pois elas representam, na verdade, espelhos da sociedade em que vivemos, queiramos ou não, pois muitos desses sujeitos sobrevivem desse trabalho, e outros até trabalham por prazer.

Portanto, é possível questionar: quem trabalha por necessidade deveria ser alvo de políticas que garantissem a inserção em outros tipos de trabalhos? Quem trabalha por prazer deveria ter uma legislação trabalhista que lhe garantisse direitos que outros trabalhadores já conquistaram? Como identificar esses perfis? Estas são questões para futuros estudos na Geografia..

\footnotetext{
Este artigo resulta da junção adaptada de dois outros trabalhos. O primeiro, que pode ser encontrado nas referências, de autoria de Ribeiro, Oliveira e Maia (2011). O segundo tem por título "As relações homocomerciais em um microterritório: $\mathrm{o}$ exemplo de um clube de boys na cidade do Rio de Janeiro", de autoria de Ribeiro e Oliveira (2014). Gostaria de agradecer ao mestrando Daniel Augusto de Oliveira Cavalcanti pela digitalização do texto, a Rafael da Silva Oliveira pela elaboração do esquema; e a ambos pelas críticas e sugestões. Agradeço, ainda, a Maria Elaine Andreoti pelas sugestões e revisão final. As ideias expressas são de exclusiva responsabilidade do autor.
}

2 Segundo Costa (2010, p. 18), “pegação é uma gíria comum da cultura gay brasileira. Significa paquerar e promover atos sexuais em lugares inusitados ou lugares específicos para isso. Ocorre na formação do mercado gay nas grandes cidades, casas fechadas destinadas à pegação ou que oportunizam determinados atos. Esses ambientes reproduzem formas de 'cantos' e labirintos escuros por onde os sujeitos transitam e promovem atos sexuais". 
3 Os boys que frequentam um determinado private club (sauna) possuem apenas uma relação contratual verbal, ou seja, não existe vínculo empregatício formalizado entre as partes. Eles apenas têm que registrar a carteira de identidade no estabelecimento, pagar já na entrada a taxa relativa ao uso do armário e sua permanência a partir do horário de trabalho estabelecido com o proprietário/gerente.

$4 \quad$ Segundo o site do projeto, ele foi "idealizado a partir das experiências de jovens frequentadores do Grupo Pela Vidda (RJ), buscando-se conhecer e avaliar melhor as práticas de prevenção, educação e promoção da saúde em relação às DST e AIDS. O estudo foi orientado a partir do aumento de dados epidemiológicos de DST e AIDS, principalmente infecção por HIV, envolvendo jovens (16 a 30 anos). A proposta objetivou um levantamento socioeducativo em saunas gays junto a jovens envolvendo o seu conhecimento acerca de práticas de prevenção e educação utilizadas em suas relações homoeróticas e homocomerciais. O projeto firmou parceria com saunas gays onde há frequência de garotos de programa e drags-queens, que se apresentam em shows, além de bares, boates, raves e quiosques, todos com práticas homocomerciais, com vista à formação de agentes mobilizadores" (extraído de www.pelavidda.org.br/babadao.html, acessado em fevereiro de 2011).

\footnotetext{
5 Os autores preferiram manter em sigilo o
} nome e o endereço do clube.

6 Relacionamentos são mantidos por alguns boys e clientes fora das dependências do clube, sendo que alguns chegam a ser estáveis, estabelecendo diferentes graus de amizade e envolvimento.

\section{Referências}

CAMPOS, Heleniza Ávila. Permanências e mudanças no quadro de requalificação de cidades brasileiras: o caso das territorialidades do sexo na área central de Recife. Revista Território, v. 5, n. 9, p. 25 43, 2000.

COSTA, Benhur Pinós da. Espaço urbano, cotidiano, cultura e espaços de proximidade: 0 caso das microterritorializações de sujeitos orientados para o mesmo sexo. 2010 (mimeo).

GOMES, Paulo Cesar da Costa. O lugar do olhar: elementos para uma geografia da visibilidade. Rio de Janeiro: Bertrand Brasil, 2013.

KAUFMANN, Vincent. Re-thinking mobility: contemporary sociology. Hampshire: Ashgate Publishing, 2002.

MAIA, Gessé da Silva. Os territórios fechados da prostituição masculina na cidade do Rio de Janeiro: o exemplo das saunas. Monografia de Pós-Graduação (lato sensu) em Políticas Territoriais no estado do Rio de Janeiro pela Universidade do Estado do Rio de Janeiro. Rio de Janeiro: Uerj, 2007.

MATTOS, Rogério Botelho. A dinâmica dos espaços da prostituição na cidade do Rio de Janeiro: 1840-1940. In: RIBEIRO, Miguel Angelo (org.). Território e prostituição na metrópole carioca. São João de Meriti/RJ: Ecomuseu Fluminense, 2002, p. 57-87.

MATTOS, Rogério Botelho. RIBEIRO, Miguel Angelo Campos. Territórios da prostituição nos espaços públicos da área central do Rio de Janeiro. In: Boletim Goiano, v. 15, n. 1, p. 57 - 79, 1995. 
OLIVEIRA, Rafael da Silva. Do espaço fechado ao espaço coletivo: o balé do lugar em meio à territorialidade da prostituição dos travestis na área central de Nova Iguaçu, RJ. In: RIBEIRO, Miguel Angelo. Território e prostituição na metrópole carioca. $1^{\mathrm{a}}$ ed. São João de Meriti/RJ: Ecomuseu Fluminense, 2002, p. 141-159.

OLIVEIRA, Rafael da Silva. Mobilidades transgressoras, geografias ignoradas: itinerários e emaranhamentos envolvendo territorialidades de garimpeiros no Suriname. (2014) Tese (doutorado em Geografia) Programa de Pós-Graduação em Geografia Humana, USP, São Paulo.

O GLOBO. Rio de Janeiro, 22 abr. 2001, p. 17.

ORNAT, Márcio José. Sobre espaço, gênero e sexualidade. Terr@ Plural, n. 2, p. 309$322,2008$.

PERLONGHER, Néstor O. O negócio do michê - a prostituição viril em São Paulo. São Paulo: Brasiliense, 1987.

RAFFESTIN, Claude. Por uma geografia do poder. São Paulo: Ática, 1993.

RIBEIRO, Miguel Angelo. Prostituição de rua e turismo: a procura do prazer na cidade do Rio de Janeiro. In: RODRIGUES, Adyr Apparecida Balastreri (org.). Turismo. Modernidade. Globalização. São Paulo: Hucitec, 1997, p. 102-118.

RIBEIRO, Miguel Angelo; OLIVEIRA, Rafael da Silva; MAIA, Gessé da Silva. Dinâmica e espacialidade das saunas de boys na cidade do Rio de Janeiro. In: RIBEIRO, Miguel Angelo; OLIVEIRA, Rafael da Silva (orgs.). Território, sexo e prazer: olhares sobre $\mathrm{o}$ fenômeno da prostituição na geografia brasileira. Rio de Janeiro: Gramma, 2011, p. 89 - 101.

SACK, Robert D. Human territoriality it's theory and history. Cambridge: Cambridge University Press, 1986.

SEAMON, David. Body-subject, time-space routines and place-ballets. In: BUTTIMER, Ane; SEAMON, David (eds). The Humam Experience of Space and Place. New York: St. Martin's Press, 1980, p. 148-165.

SILVA, José Carlos. Monik Cretton. Uma mulher à frente do seu tempo. Revista S!, n. 139 , mar. 2014 , p. 3.

SILVA, Joseli Maria et al. O corpo como elemento das geografias feministas e queer: um desfio para a análise no Brasil. In: SILVA, Joseli Maria; ORNAT, Márcio José; CHIMIN JUNIOR, Alides Baptista (orgs.). Geografias malditas: corpos, sexualidades e espaços. Ponta Grossa: Todapalavra, 2013, p. 85-142.

SILVA, Joseli Maria; ORNAT; Márcio José. Sobre sexualidade e espaço: prostituição e território travesti'. In: RIBEIRO, Miguel Angelo; OLIVEIRA, Rafael (orgs). Território, sexo e prazer: olhares sobre o fenômeno da prostituição na geografia brasileira. Rio de Janeiro: Gramma, 2011, p. 167-184.

SIMÕES, Manoel Ricardo. A cidade estilhaçada: reestruturação econômica e emancipações municipais na Baixada Fluminense. (2006) Tese (doutorado em Geografia) - Universidade Federal Fluminense, Niterói.

SOUZA, Marcelo José Lopes de. O território: sobre espaço e poder autonomia e desenvolvimento. In: CASTRO, Iná Elias; 
Dinâmica, Espacialidade e Relações

Homocomerciais: o exemplo das saunas de boys

na urbe carioca

GOMES, Paulo César da Costa; CORRÊA, Roberto Lobato. Geografia: conceitos e temas. Rio de Janeiro: Bertrand Brasil, 1995, p. 77-116.

SOUZA, Marcelo José Lopes de. Os conceitos fundamentais da pesquisa socioespacial. $1^{\text {a }}$ ed. Rio de Janeiro: Bertrand Brasil, 2013.

TUAN, Yi-Fu. Topofilia. São Paulo: Difel, 1980.

\section{Site consultado:}

www.pelavidda.org.br/babadao.html

Recebido em 15 de outubro de 2014. Aceito em 07 de dezembro de 2014.

Miguel Angelo Ribeiro 